\title{
The Contribution of a Collagen Patch Coated With Fibrin Glue in Sealing Upper Gastrointestinal Defects: An Experimental Study
}

\author{
GREGORY CHRISTODOULIDIS ${ }^{1}$, ATHINA A. SAMARA ${ }^{1}$, THEODOROS FLOROS ${ }^{1}$, \\ KOSTAS-SOTIRIOS KARAKANTAS ${ }^{1}$, PROKOPIS-ANDREAS ZOTOS ${ }^{1}$, \\ ANTONIOS KOUTRAS ${ }^{2}$ and KONSTANTINOS TEPETES ${ }^{1}$ \\ ${ }^{1}$ Laboratory of Experimental Surgery, University of Thessaly, Larissa, Greece; \\ ${ }^{2} 1^{\text {st }}$ Department of Obstetrics and Gynecology, Alexandra Maternity Hospital, \\ National and Kapodistrian University of Athens, Athens, Greece
}

\begin{abstract}
Background/Aim: We aimed to evaluate the safety and efficacy of sealing primary upper gastrointestinal (GI) perforations with a collagen patch coated with fibrin glue (Tachosil $\left.{ }^{\circledR}\right)$. Materials and Methods: Thirty New Zealand rabbits were used in this study. An iatrogenic gastric perforation was created, and primary repair was performed on the control group. Tachosil ${ }^{\circledR}$, without suturing the deficit, was used in the intervention group. Results: Leakage was observed in $3(20 \%)$ and 2 rabbits (13.3\%) in the control and intervention group, respectively; however, the difference was not statistically significant $(p=0.62)$. Moreover, adhesions formed in 10/15 and all rabbits in the intervention and control group, respectively $(p=0.014)$; however, based on the Zuhlke adhesion's classification, there was no statistically significant difference between the two groups. Conclusion: A collagen patch coated with fibrin glue is not a replacement but can be considered a safe option for the reinforcement of suturing, preventing leakages in the upper GI tract.
\end{abstract}

Gastrointestinal (GI) leakage is a common and significant complication in routine clinical surgical practice, with increasing morbidity and mortality (1). Leakages of the GI tract can be the result of a perforation (spontaneous or iatrogenic) or a surgical anastomosis complication (2). Wide-ranging complications are associated with GI leakages, including local abscess formation, sepsis, and even multiple organ system

This article is freely accessible online.

Correspondence to: Athina A. Samara, Laboratory of Experimental Surgery, University of Thessaly, Larissa 41110, Greece. Tel: +30 2413501701,e-mail: at.samara93@gmail.com

Key Words: Upper GI, perforation, leakages, Tachosil ${ }^{\circledR}$, fibrin glue. failure in cases of delayed diagnosis (3). Furthermore, prolonged hospitalization due to anastomotic leakages has been associated with long-term decreased quality of life (4).

Several clinical and experimental studies have been conducted to increase the safety of anastomoses and primary repaired injuries (gastric or duodenal perforation), thereby decreasing the incidence of these complications $(5,6)$. Through several trials, a variety of materials have been evaluated to decrease the incidence of leakage and any related consequences (7-9). Experimental studies have provided promising findings; however, results are not easily reproducible in human clinical studies.

Tachosil $^{\circledR}$ (haemostatic surgical patch; Nycomed, Linz, Austria) is a fibrin sealant patch indicated for use as an adjunct in hepatic and cardiovascular surgery when control of bleeding using classic surgical techniques is ineffective or impossible (10). Several studies have examined the effectiveness of Tachosil $^{\circledR}$ as an additional reinforcement to pancreatic stump closure, with unclear results (11). Conversely, Tachosil ${ }^{\circledR}$ has been associated with highly promising results when applied to the reinforcement of colorectal anastomoses in both experimental and clinical settings (12-14).

To the best of our current knowledge, Tachosil ${ }^{\circledR}$ has never been utilized as a reinforcement material in upper GI anastomoses and the primary closure of upper GI perforations. In the present experimental design using New Zealand rabbits, we aimed to determine and evaluate the safety and efficacy of sealing anastomoses and primary closure of upper GI perforations with a collagen patch coated with fibrin glue $\left(\right.$ Tachosil $\left.^{\circledR}\right)$.

\section{Materials and Methods}

Animal models. Thirty female New Zealand rabbits - an appropriate and validated model for experimental studies and research - were 

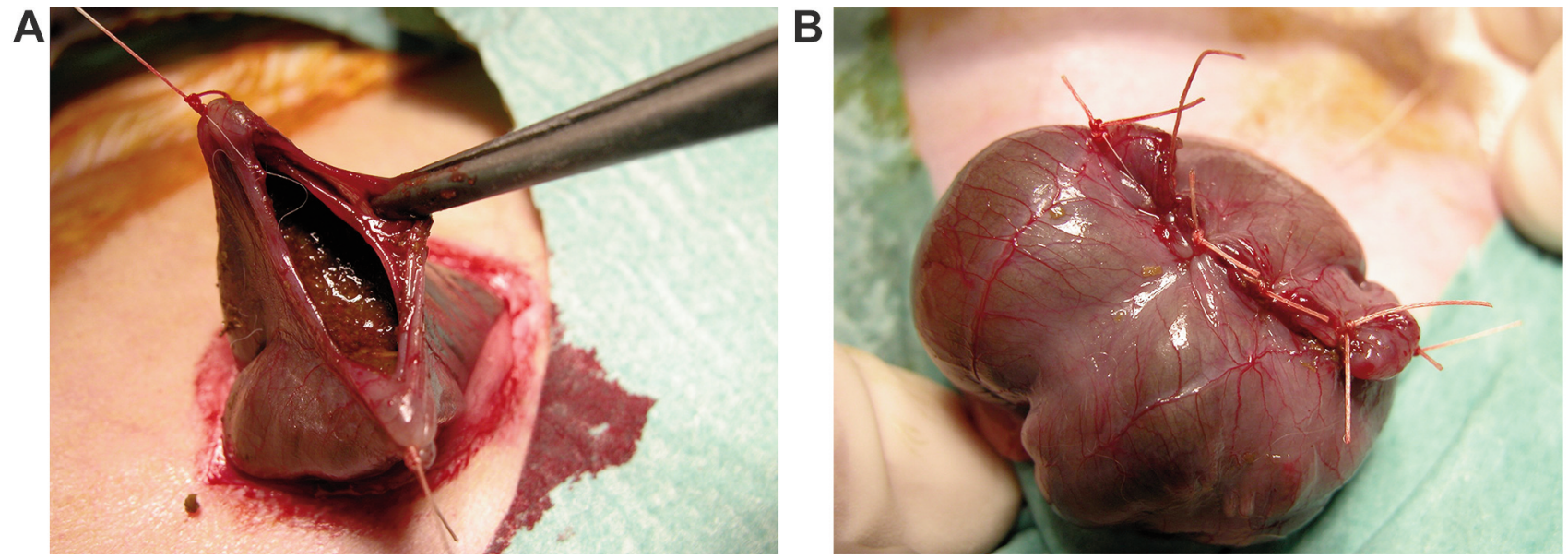

Figure 1. Intraoperative images from the control group $(A, B)$. Management of the perforated stomach involved the placement of sutures $($ Dexon $3 / 0)$ in the defect.

used as animal models in this study. The animals were kept in the Laboratory of Experimental Surgery of the University of Thessaly under controlled conditions (temperature $25 \pm 1^{\circ} \mathrm{C}$, humidity $55 \pm 5 \%$, controlled light $12 \mathrm{~h}$ per day), with the rabbits fasting the evening prior to surgery.

Research involving animals. The present study was conducted in accordance with the Declaration of Helsinki concerning animal and Human Rights, and was approved by the Medical School of the University of Thessaly Ethics Committee.

Experimental protocol and surgical procedures. Rabbits were anesthetized by injecting intravenously a mixture of ketamine hydrochloride $(15 \mathrm{mg} / \mathrm{kg})$ and midazolam $(1 \mathrm{mg} / \mathrm{kg})$; anesthesia was maintained with intravenous infusion of ketamine hydrochloride at a rate of $60 \mathrm{mg} / \mathrm{kg} / \mathrm{h}$. Initially, the rabbits' abdomen was shaved and excess hair was removed with a piece of tape. Basic surgical principles including safety and minimization of surgical time were strictly followed to reduce suffering of the rabbits and prevent secondary infections, which could have affected the experiment's outcome. The rabbits' skin was disinfected and midline incisions $(3.5-4.0 \mathrm{~cm})$ of both the skin and muscle layer were performed. The surgeon created an artificial hole in the posterior gastric wall after identifying and pulling the stomach forward. The abdominal wall was closed using an absorbable running suture (Vicryl 2.0) in the muscle layer and a non-absorbable interrupted suture (Nylon 3.0) with inverted knots in the skin.

Management of the perforated stomach involved the placement of sutures (Dexon 3/0) in the control group $(n=15)$ (Figure 1A and $\mathrm{B})$, whereas in the intervention group, management required only the application of Tachosil ${ }^{\circledR}$. Additionally, an omenoplasty was performed on each rabbit in the control group by the same surgeon, where a flap of the animal's greater omentum was used to cover the defect. In the intervention group $(n=15)$, the yellow surface of the Tachosil ${ }^{\circledR}$ was placed directly on the created defect without any further handling. In accordance with the study's protocol, the patch was required to cover at minimum 1-2 $\mathrm{cm}$ beyond the margins of the defect (Figure 2).

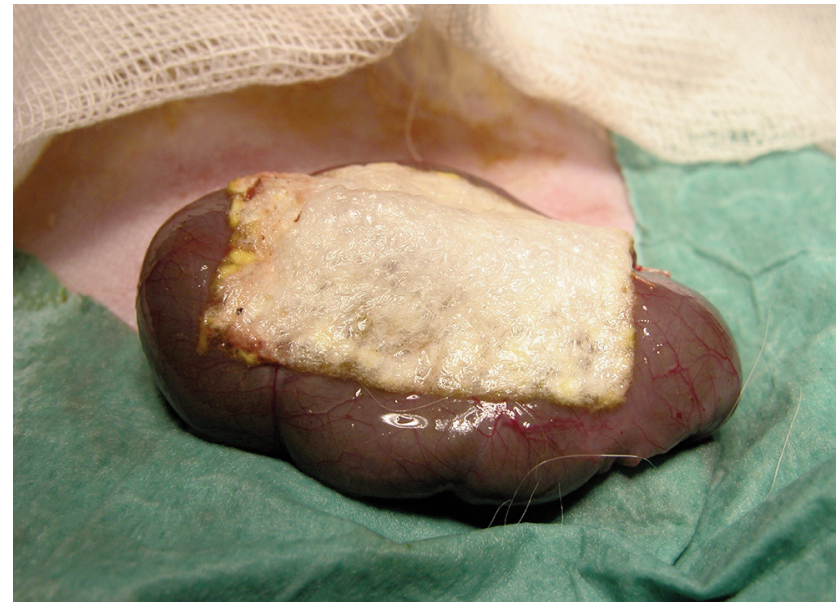

Figure 2. Intraoperative image from the intervention group. Placement of the yellow surface of the Tachosil ${ }^{\circledR}$ directly on the created defect without any further handling. The patch covers a minimum of $1-2 \mathrm{~cm}$ beyond the margins of the defect.

Post-operatively, rabbit cages were placed in a room with an estimated temperature of $25-28^{\circ} \mathrm{C}$, where the animals were carefully evaluated daily by a member of the medical team. On the $15^{\text {th }}$ postoperative day, the animals were euthanized with exsanguination, following intravenous administration of sodium pentobarbital (30 $\mathrm{mg} / \mathrm{kg}$ ), in accordance with the Institutional Animal Care and Use Committees' (IACUC) guidelines. All euthanized rabbits were submitted to a second laparotomy for the purpose of evaluating both the peritoneal cavity and surgical site.

Fibrin sealant. Tachosil ${ }^{\circledR}$ is widely used for intraoperative hemostasis. It consists of an active yellow side with human thrombin $\left(2.0 \mathrm{IU} / \mathrm{cm}^{2}\right)$ and human fibrinogen $\left(5.5 \mathrm{mg} / \mathrm{cm}^{2}\right)$, as well as a supportive white side made of collagen. After thawing and 
warming to $37^{\circ} \mathrm{C}$, the two solutions were mixed and approximately $0.4 \mathrm{ml}$ were applied directly on the defect.

Pathology analysis. Standard pathology methods and procedures were followed. Diagnosis was based on formalin fixed, paraffin-embedded hematoxylin and eosin-stained sections that were $4 \mu \mathrm{m}$ thick.

Statistical analysis. Data were analyzed using SPSS v.25 (IBM, Chicago, IL, USA), with quantitative variables presented as absolute and relative frequencies. Chi-square tests were used for comparisons between the two groups. A $p$-value $<0.05$ was considered statistically significant.

\section{Results}

New Zealand rabbits were divided into two groups of 15 animals (group A - control, group B- Tachosil ${ }^{\mathbb{R}}$ ). A total of two rabbits, one from each group, deceased on the $3^{\text {rd }}$ and $4^{\text {th }}$ postoperative day, respectively, due to abdominal sepsis from macroscopic leakage and peritonitis $(p=1)$. In group A (control), an additional severe inflammatory reaction due to leakage was observed in two more animals (3 in total-20\%), whereas in group B an intra-abdominal abscess due to leakage was detected in one rabbit (2 in total-13.3\%) (Table I). There was no statistically significant difference regarding the presence of postoperative leakage between the two groups $(p=0.62)$. The healing of the repaired defect was excellent in the animal that survived until the $15^{\text {th }}$ postoperative day ( $n=14$ and $n=14$, respectively).

Adhesions. Adhesions were evaluated using Zuhlke classifications (15); they were most commonly identified on the right upper quadrant of the abdomen. In group A (control), $46.6 \%$ of the animals had adhesions categorized as I-II according to the Zuhlke classification, with $26.6 \%$ classified as III and $20 \%$ as IV. Within group B (Tachosil ${ }^{\circledR}$ ), $42.8 \%$ of rabbits showed adhesions categorized as I-II, with $21.5 \%$ classified as III, $0 \%$ as IV, and no adhesions were identified in 5 animals (Table II). There was a statistically significant difference regarding the presence of adhesions between the two groups $(p=0.014)$, however, there was no statistically significant difference related to Zuhlke's classification.

Histopathological evaluation. Inflammation, revascularization and fibroblasts were present in the samples of both groups. Mucosal and serosal continuity was normal in all surviving models. (Figures 3 and 4).

\section{Discussion}

A significant number of trials have been conducted regarding the sealing of GI anastomoses, particularly in colonic anastomoses and duodenal trauma related defects $(16,17)$. Most of these trials have been experimental and suggest
Table I. Complication rates in each group.

\begin{tabular}{lccc}
\hline $\begin{array}{c}\text { Group A } \\
\text { (control) }\end{array}$ & $\begin{array}{c}\text { Group B } \\
\text { (Tachosil) }\end{array}$ & $p$-Value* \\
\hline Mortality & $1 / 15(6.7 \%)$ & $1 / 15(6.7 \%)$ & 1 \\
Leakage & $3 / 15(20 \%)$ & $2 / 15(13.3 \%)$ & 0.62 \\
\hline
\end{tabular}

*Chi-square test.

Table II. Macroscopic adhesion classification according to Zuhlke.

\begin{tabular}{lccc}
\hline & $\begin{array}{c}\text { Group A } \\
\text { (control) }\end{array}$ & $\begin{array}{c}\text { Group B } \\
\text { (Tachosil) }\end{array}$ & $p$-Value* \\
\hline No adhesions & $0 / 15(0 \%)$ & $5 / 15(35.7 \%)$ & 0.014 \\
I - II Zuhlke & $7 / 15(46.6 \%)$ & $6 / 15(40 \%)$ & 0.71 \\
III Zuhlke & $4 / 15(26.6 \%)$ & $3 / 15(20 \%)$ & 0.66 \\
IV Zuhlke & $3 / 15(20 \%)$ & $0 / 15(0 \%)$ & 0.06 \\
\hline
\end{tabular}

Bold value indicates statistical significance.

sealing with different materials such as omental flaps, meshes, amniotic membranes or small intestinal submucosa (18-20). A few human studies have also been performed with conflicting results (11-12).

A study by Karagoz-Avci et al. (21) compared classic primary surgical repair and suture-less repairing techniques utilizing fibrin glue and a polyethylene-glycol hydrogel material, used as an adjunct to standard methods of dural repair (Duraseal ${ }^{\circledR}$ ). The authors evaluated both the pathological and histological findings, measuring the bursting pressure of the repaired area by insufflating air. The results were similar between the groups and no harmful effects were observed when suture-less techniques were used (21).

Saygun et al. (22) evaluated the reinforcing ability of Eptfe grafts with histoacryl glue in an experimental model of duodenal trauma. No leakages, abscesses or deep surgical site infections were found in the Eptfe-HAG group, and the integrity of the graft into the intestinal serosa remained still strong ten days after the repair (22). Another experimental study evaluated the use of human amniotic membrane (HAM) in repairing duodenal perforation in animal models (23); this study revealed better histological results compared with simple suturing, but not significantly improved surgical findings (23).

Furthermore, Hoepnner et al. (24) examined the use of small intestinal submucosa (SIS) in sealing staples of colonic anastomoses in a porcine model. No significant differences were found regarding complications or adverse effects. The same research team also applied SIS on a colonic anastomosis of a rodent model and detected significantly improved anastomotic healing, with no significant complications in the study group (25). 


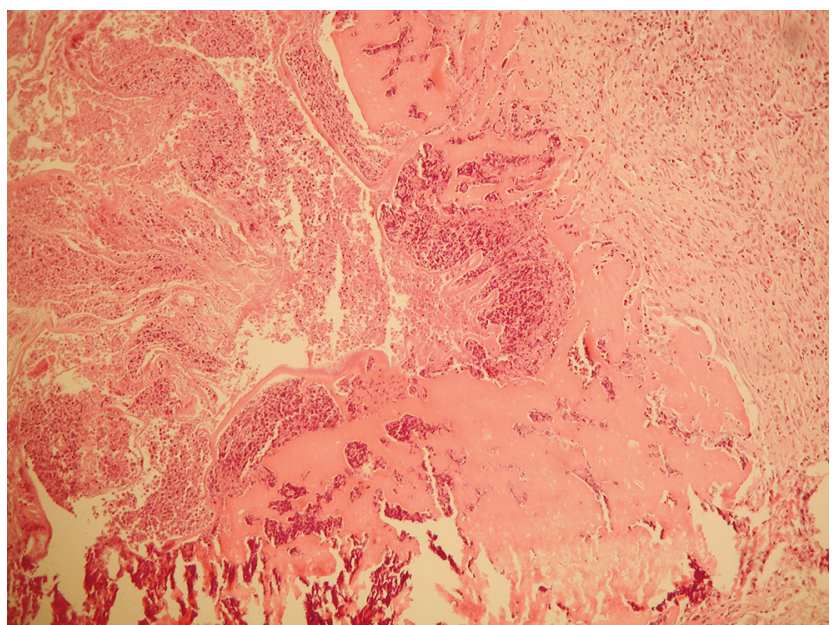

Figure 3. Histopathology image of the defect healing in the control group.

A few studies have been published related to the use of Tachosil ${ }^{\circledR}$ for the sealing of colorectal anastomoses (12-14). Poomergaard et al. conducted a study with technically insufficient mice colon anastomoses and found a significantly lower leakage rate in the group where Tachosil ${ }^{\circledR}$ was applied (26). However, most of the studies were experimental and conducted on animal models, with only one clinical study using Tachosil ${ }^{\circledR}$ in 24 patients (12). Additional clinical studies, especially randomized clinical studies in humans should be performed to investigate and evaluate the safety and efficacy of this material.

On the other hand, there has been only one study that evaluated the use of Tachosil ${ }^{\circledR}$ on upper GI anastomoses or defects (27). Application of the fibrin coated patch on esophageal anastomoses was found to be feasible on both esophagogastrostomy and esophagojejunostomy.

Animal models are valuable for evaluating pathophysiological mechanisms and may be used to test measures, which aim to prevent the risk of leakage, such as external anastomotic coating. This study presents our initial experience with intraoperative topical application of Tachosil ${ }^{\circledR}$ on perforated gastric ulcers, where our primary goal was to prove that its application is technically feasible. This goal was proven in all experimental animals, and highly promising results regarding leakages and no severe adverse events such as adhesion formation or stenosis were obtained.

An important result of the present study is the fact that the Tachosil ${ }^{\circledR}$ group showed fewer adhesions than the control group. Similar results were reported by two experimental studies where Tachosil $^{\circledR}$ reduced postoperative adhesions following laparoscopic surgery on a rat model and did not provoke adhesion formation in a pig model $(28,29)$.

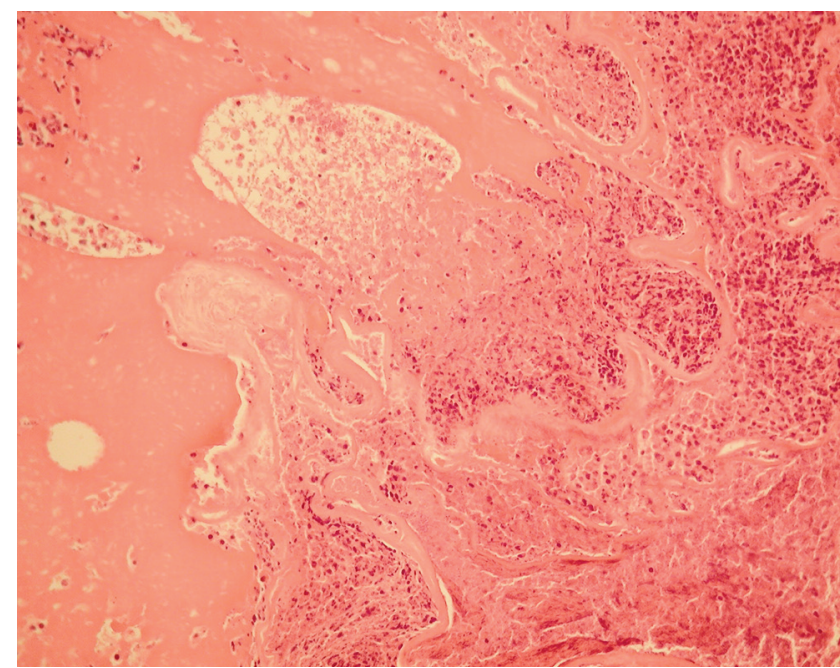

Figure 4. Histopathology image of the defect healing in the intervention group.

The results of the present study demonstrate that while Tachosil ${ }^{\circledR}$ cannot replace conventional surgical techniques, it can play a supportive role in reinforcing primary suturing of upper GI deficits in patients at risk for postoperative leakage. Specifically, when risk factors including old age, obesity, malnutrition, severe comorbidities (particularly diabetes), prolonged surgery time, perioperative blood transfusions and chemoradiotherapy are present, surgeons must consider the use of Tachosil ${ }^{\circledR}$ as a reinforcement preventing leakages.

Before the appraisal of our results, several limitations must be considered. This is an experimental study with a small number of animals; thus, the generalization of results is limited. To our current knowledge, this is the first study demonstrating the application of Tachosil ${ }^{\circledR}$ for upper GI perforations. Additionally, all procedures were performed by the same team which reduced heterogeneity of the study.

In conclusion, a collagen patch coated with fibrin glue is not a replacement but can be considered a safe option for the reinforcement of suturing, preventing gastric leakage in cases of stomach perforations and leaks in anastomoses located in the upper GI tract.

\section{Conflicts of Interest}

The Authors have no conflicts of interest to declare in relation to this study.

\section{Authors' Contributions}

All Authors have contributed equally to the study design, conduction of the experiments, and drafting and revising the manuscript. 


\section{Acknowledgements}

The Authors would like to thank Lemonia Anagnostopoulos for English language editing.

\section{References}

1 Fumagalli U, Baiocchi GL, Celotti A, Parise P, Cossu A, Bonavina L, Bernardi D, de Manzoni G, Weindelmayer J, Verlato G, Santi S, Pallabazzer G, Portolani N, Degiuli M, Reddavid $\mathrm{R}$ and de Pascale $\mathrm{S}$ : Incidence and treatment of mediastinal leakage after esophagectomy: Insights from the multicenter study on mediastinal leaks. World J Gastroenterol 25(3): 356-366, 2019. PMID: 30686903. DOI: 10.3748/wjg. v25.i3.356

2 Al-Asiry J, Lord R and Mohammed N: Management of spontaneous and iatrogenic perforations, leaks and fistulae of the upper gastrointestinal tract. Ther Adv Gastrointest Endosc 12: 2631774519895845, 2019. PMID: 31909396. DOI: $10.1177 / 2631774519895845$

3 Tuma F: Gastrointestinal tract leak: Is it one entity or spectrum of conditions? Cureus 12(9): e10458, 2020. PMID: 33072466 DOI: $10.7759 /$ cureus. 10458

4 Marinatou A, Theodoropoulos GE, Karanika S, Karantanos T, Siakavellas S, Spyropoulos BG, Toutouzas K and Zografos G: Do anastomotic leaks impair postoperative health-related quality of life after rectal cancer surgery? A case-matched study. Dis Colon Rectum 57(2): 158-166, 2014. PMID: 24401876. DOI: 10.1097/DCR.0000000000000040

5 Xing J, Liu M, Qi X, Yu J, Fan Y, Xu K, Gao P, Tan F, Yao Z, Zhang N, Yang H, Zhang C, Cui M and Su X: Risk factors for esophagojejunal anastomotic leakage after curative total gastrectomy combined with D2 lymph node dissection for gastric cancer. J Int Med Res 49(3): 3000605211000883, 2021. PMID: 33736508. DOI: 10.1177/03000605211000883

6 Trapani R, Rausei S, Reddavid R, Degiuli M and Italian Research Group for Gastric Cancer (GIRCG) Clinical Investigators: Risk factors for esophago-jejunal anastomosis leakage after total gastrectomy for cancer. A multicenter retrospective study of the Italian research group for gastric cancer. Eur J Surg Oncol 46(12): 2243-2247, 2020. PMID: 32703713. DOI: 10.1016/j.ejso.2020.06.035

7 Stergios K, Frountzas M, Pergialiotis V, Korou LM, Kontzoglou K, Stefanidis K, Nikiteas N, Perrea DN and Vaos G: The effect of TISSEEL ${ }^{\circledR}$ on colorectal anastomosis healing process in a diabetic animal experimental model. In Vivo 34(2): 659-665, 2020. PMID: 32111766. DOI: 10.21873/invivo. 11820

8 Kanellos D, Blouhos K, Pramateftakis MG, Kanellos I, Demetriades H, Sakkas L and Betsis D: Effect of 5-fluorouracil plus interferon on the integrity of colonic anastomoses covering with fibrin glue. World J Surg 31(1): 186-191, 2007. PMID: 17171478. DOI: 10.1007/s00268-006-0094-5

9 Giuratrabocchetta S, Rinaldi M, Cuccia F, Lemma M, Piscitelli D, Polidoro $\mathrm{P}$ and Altomare DF: Protection of intestinal anastomosis with biological glues: an experimental randomized controlled trial. Tech Coloproctol 15(2): 153-158, 2011. PMID: 21264676. DOI: 10.1007/s10151-010-0674-0

10 Rickenbacher A, Breitenstein S, Lesurtel $\mathrm{M}$ and Frilling A: Efficacy of TachoSil a fibrin-based haemostat in different fields of surgery - a systematic review. Expert Opin Biol Ther 9(7): 897907, 2009. PMID: 19527109. DOI: 10.1517/14712590903029172

11 Deng Y, He S, Cheng Y, Cheng N, Gong J, Gong J, Zeng Z and Zhao L: Fibrin sealants for the prevention of postoperative pancreatic fistula following pancreatic surgery. Cochrane Database Syst Rev 3: CD009621, 2020. PMID: 32157697. DOI: 10.1002/14651858.CD009621.pub4

12 De Stefano A, Bettarini F, Di Mare G and Neri A: [Enteric anastomosis and Tachosil ${ }^{\circledR}$ ]. Minerva Chir 66(3): 183-188, 2011. PMID: 21666554.

13 Nordentoft T: Sealing of gastrointestinal anastomoses with fibrin glue coated collagen patch. Dan Med J 62(5): B5081, 2015. PMID: 26050838.

14 Pantelis D, Beissel A, Kahl P, Wehner S, Vilz TO and Kalff JC: The effect of sealing with a fixed combination of collagen matrix-bound coagulation factors on the healing of colonic anastomoses in experimental high-risk mice models. Langenbecks Arch Surg 395(8): 1039-1048, 2010. PMID: 20680329. DOI: $10.1007 / \mathrm{s} 00423-010-0703-5$

15 Zühlke HV, Lorenz EM, Straub EM and Savvas V: [Pathophysiology and classification of adhesions]. Langenbecks Arch Chir Suppl II Verh Dtsch Ges Chir: 1009-1016, 1990. PMID: 1983476

16 Plat VD, Bootsma BT, van der Wielen N, Straatman J, Schoonmade LJ, van der Peet DL and Daams F: The role of tissue adhesives in esophageal surgery, a systematic review of literature. Int J Surg 40: 163-168, 2017. PMID: 28285057. DOI: 10.1016/j.ijsu.2017.02.093

17 Stergios K, Kontzoglou K, Pergialiotis V, Korou LM, Frountzas M, Lalude O, Nikiteas $\mathrm{N}$ and Perrea DN: The potential effect of biological sealants on colorectal anastomosis healing in experimental research involving severe diabetes. Ann R Coll Surg Engl 99(3): 189-192, 2017. PMID: 27917665. DOI: 10.1308/rcsann.2016.0357

18 Senol M, Altintas MM, Cevık A, Altuntas YE, Barisik NO, Bildik $\mathrm{N}$ and Oncel M: The effect of fibrin glue on the intensity of colonic anastomosis in the presence and absence of peritonitis: an experimental randomized controlled trial on rats. ISRN Surg 2013: 521413, 2013. PMID: 23401799. DOI: $10.1155 / 2013 / 521413$

19 Vakalopoulos KA, Daams F, Wu Z, Timmermans L, Jeekel JJ, Kleinrensink GJ, van der Ham A and Lange JF: Tissue adhesives in gastrointestinal anastomosis: a systematic review. J Surg Res 180(2): 290-300, 2013. PMID: 23384970. DOI: 10.1016/ j.jss.2012.12.043

20 Spotnitz WD: Fibrin Sealant: The only approved hemostat, sealant, and adhesive-a laboratory and clinical perspective. ISRN Surg 2014: 203943, 2014. PMID: 24729902. DOI: 10.1155/ 2014/203943

21 Karagöz Avci S, Yüceyar S, Aytaç E, Bayraktar O, Erenler I, Ustün H, Uzun H and Ertürk S: Comparison of classical surgery and sutureless repair with DuraSeal or fibrin glue for duodenal perforation in rats. Ulus Travma Acil Cerrahi Derg 17(1): 9-13, 2011. DOI: $10.5505 /$ tjtes.2011.13914

22 Saygun O, Topaloglu S, Avsar FM, Ozel H, Hucumenoglu S, Sahin M and Hengirmen S: Reinforcement of the suture line with an ePTFE graft attached with histoacryl glue in duodenal trauma. Can J Surg 49(2): 107-112, 2006. PMID: 16630421

23 Moslemi S Md, Joraghi SA Md, Roshanravan R Md, Ghahramani L Md, Mohammadianpanah M Md, Hosseinzadeh 
M Md, Rezaianzadeh A Md, Hussein AM Md, Najibpour N Md and Hosseini SV Md: Effect of human amniotic membrane on prevention of colorectal anastomosis leakage in cases with neoadjuvant radiotherapy: An experimental animal study. Iran J Med Sci 41(6): 501-506, 2016. PMID: 27853330

24 Hoeppner J, Marjanovic G, Helwig P, Hopt UT and Keck T: Extracellular matrices for gastrointestinal surgery: ex vivo testing and current applications. World J Gastroenterol 16(32): 40314038, 2010. PMID: 20731016. DOI: 10.3748/wjg.v16.i32.4031

25 Hoeppner J, Crnogorac V, Marjanovic G, Jüttner E, Keck T, Weiser HF and Hopt UT: Small intestinal submucosa for reinforcement of colonic anastomosis. Int J Colorectal Dis 24(5): 543-550, 2009. PMID: 19184065. DOI: 10.1007/s00384-009$0637-y$

26 Pommergaard HC, Achiam MP, Burcharth J and Rosenberg J: Decreased leakage rate of colonic anastomoses by tachosil coating: an experimental study. Int Surg 99(4): 359-363, 2014. PMID: 25058765. DOI: 10.9738/INTSURG-D-13-00093.1

27 Haverkamp L, Ruurda JP and van Hillegersberg R: Technical Feasibility of TachoSil Application on Esophageal Anastomoses. Gastroenterol Res Pract 2015: 534080, 2015. PMID: 26101523. DOI: $10.1155 / 2015 / 534080$
28 Nohuz E, Darcha C, Moreno W, Tamburro S, Yanez M, Mulliez A, Grizard G, Mage G and Canis M: Efficiency of TachoSilA ${ }^{\circledR}$ to prevent postsurgical adhesion development on laparoscopic rat model. Gynecological Surgery 6(4): 323-329, 2019. DOI: 10.1007/s10397-009-0496-0

29 Erb MA, Claus T, Hartrumpf M, Bachmann S and Albes JM: The use of Tachosil surgical patch or fibrin glue in coronary artery surgery does not affect quality of anastomosis or provoke postoperative adhesions in pigs. Eur J Cardiothorac Surg 36(4): 703-707, 2009. PMID: 19699105. DOI: 10.1016/j.ejcts. 2009.04.028

Received June 8, 2021

Revised June 23, 2021

Accepted June 24, 2021 